\title{
Adsorption Performance of Roxithromycin on Multi-walled Carbon Nanotubes in Water
}

\author{
LIU Zhen-zhong
}

(School of Architecture Engineering of Nanchang University,Nanchang, Jiangxi Nanchang, 330031, China)

Key words: multi-walled carbon nanotubes; antibiotics; roxithromycin; adsorption

Abstract: The adsorption of roxithromycin from aqueous solution onto multied-walled carbon nanotubes was studied. The gravimetric method can be adopted for calculating the adsorption isotherm and kinetic curves of roxithromycin onto the carbon nanotubes. The influential factors including the $\mathrm{pH}$ and humic acid on the adsorption efficiency were investigated in the paper. Experimental results indicated that the adsorption kinetics and isotherm can be well described by using a pseudo-second-order rate model and Freundlich isotherm, respectively. The adsorption capacity of roxithromycin decreased with the addition of erythromycin in water. The adsorption capacity of roxithromycin decreased when the $\mathrm{pH}$ was less 4 while adsorption capacity increased when the $\mathrm{pH}$ more than 4 . The promotion action of the adsorption of roxithromycin onto multi-walled carbon nanotubes happened when the concentration of humic acids was less $25 \mathrm{mg} / \mathrm{L}$ while the inhibition action happened when the concentration of humic acids was more than $25 \mathrm{mg} / \mathrm{L}$. CLC number: X53

Document code: A

The extensive use of antibiotics has been paid much more attention in the fields of medicine,livestock breeding and aquatic product. It has been reported that the total usage of antibiotics was about 162,000 tons in China in $2013^{[1,2]}$. The majority of antibiotics are poorly adsorbed and thus excreted by humans or animals in faeces and urine, and can directly enter natural waters and soil. Moreover, the wastewater generated by the manufacturing operations of the pharmaceutical industry could be discarded into natural water systems ${ }^{[3,4]}$. Conventional treatment process hardly remove or degradation the antibiotics in water and wastewater ${ }^{[5-7]}$. The pollutants pass through the water and wastewater treatment proocesses, enter into the aquatic environment and subsequently threaten aquatic ecology, drinking water security and human health ${ }^{[8-11]}$.

Macrolides are synthetic broad-spectrum antibiotics commonly used in human and medicine treatment. They belong to one of the most commonly used families of antibiotics, although occurrence of macrolides in aquatic environment is at low concentrations, due to their poor water solubility ${ }^{[12]}$. Roxithromycin is one of macrolides antibiotics, which was frequently found in water because of extensive usage,large production, long half-life period. The quantity order of roxithromycin of $\mu \mathrm{g} / \mathrm{Lwas}$ often detected in Germanic ground water and wastewater plant. Xu Huaihai found that roxithromycin concentration ranked highest on antibiotics indicator in the detection of pearl river quality ${ }^{[13]}$. It is necessary to removal macrolides antibiotics such as roxithromycin in water.

Carbon nanotubes with high specific suface area and bound micropore are widely applied at environment protection field which has better adsorption capacity than activated carbon. Researches $^{[14]}$ indicated that carbon nanotubes have strong adsorption capacity on varieties types of pollutants such as chlorobenzene, trihalomethane, phenylamine, nitrophenol and heavy metal ions et al. $\mathrm{Li}^{[15]}$ and $\mathrm{Wang}^{[16]}$ et al found that carbon nanotubes have exellent adsorption capacity which can fit Langmuir and Freundlich adsorption isotherm well by studying $\mathrm{Pb}^{+}$adsorption efficient on 
carbon nanotube in water. Shen Xiu'e ${ }^{[17]}$ regarded that carbon nanotubes could reach the adsorption balance in short interval accordance with preudo-second order kinetics which adsorbed the anbiotics of sulfathiazole and ciprofloxacin. Currently, seldom references about roxithromycin adsorbed by carbon nanotube were reported .

The objectives of this study are to (1) investigate the roxithromycin sorption capacity and reaction kinetics on multi-walled carbon nanotubes; (2) found the effect of the erythromycin on roxithromycin removal efficiencies on multi-walled carbon nanotubes; (3) determine the effects of $\mathrm{pH}$ and $\mathrm{HA}$.

\section{Materials and Methods}

\section{Materials}

Roxithylamine,ammonium dihydrogen phosphate, $\mathrm{HCl}$ and $\mathrm{NaOH}$ were analytical reagent,some chemicals were chromatographically reagent such as acetonitrile and methyl alcohol. Ultrapure water supplied was used to prepare all the reagents and solutions.

\section{Pretreatment of multi-walled carbon nanotubes}

Some quantity multi-walled carbon nanotubes were immersed into the $250 \mathrm{~mL}$ of nitric acid(3 $\mathrm{mol} / \mathrm{L}$ ) in $500 \mathrm{~mL}$ flask at room temperature, shaked $24 \mathrm{~h}$ with ultrasound, then washed with ultrapure water to neutral $\mathrm{pH}$ and dried in an oven at $393 \mathrm{~K}$ for $8 \mathrm{~h}$, furthermore, crushed into $0.001 \mathrm{mg}$ powder.

\section{Adsorption kinetic and isotherm experiment}

The experiments were carried out in a set of $250 \mathrm{~mL}$ erlenmeyer flasks with the addition of 100 $\mathrm{mL}$ of $20 \mathrm{mg} / \mathrm{L}$ roxithromycin or both $20 \mathrm{mg} / \mathrm{L}$ roxithromycin and erythromycin solutions and 50mg MWCNT. The suspensions were shaken on an orbit shaker at $180 \mathrm{r} / \mathrm{min}$ for hours at $298 \mathrm{~K}$. The mixture was filtered through $0.45 \mu \mathrm{m}$ membrane. The filtrate was analyzed with HPLC. The quantity of removal roxithromycin was calculated by the difference of the initial and residual amounts of roxithromycin in solution divided by the weight of the adsorbent.

The concentration of roxithromycin was analyzed by the high performance liquid chromatography (HPLC) at a 210-nm wavelength. The apparatus was configured with Waters 2695 dual wavelength detector, Waters 717 Plus automatic sampler and Waters 1525 pumps. Roxithromycin was separated by $\mathrm{C}_{18}$ column $(150 \mathrm{~mm} \times 4.6 \mathrm{~mm}, 5 \mu \mathrm{m}$ Waters $)$.

In order to study the adsorption isotherm of roxithromycin on the MWCNT, some initial roxithromycin concentrations were prepared and $50 \mathrm{mg}$ MWCNT was added into each flask covered with glass stopper and the flasks were then placed in shaker until equilibrium point was reached. In this case, the solution $\mathrm{pH}$ was kept original without any $\mathrm{pH}$ adjustment.

\section{Influence factors experiment}

Experiments to determine the effect of solution $\mathrm{pH}$ values on roxithromycin removal were performed by adding $100 \mathrm{mg}$ of MWCNT into the vessel containing $100 \mathrm{~mL}$ of $20 \mathrm{mg} \bullet \mathrm{L}^{-1}$ roxithromycin solution. The $\mathrm{pH}$ of the solutions was adjusted with $0.01 \mathrm{~mol} / \mathrm{L} \mathrm{HCl}$ and $\mathrm{NaOH}$ to designated values in the range of $1-11$.

Experiments determining the effect of HA on roxithromycin removal were performed by adding $100 \mathrm{mg}$ of MWCNT into the vessel containing $100 \mathrm{~mL}$ of $20 \mathrm{mg} \bullet \mathrm{L}^{-1}$ roxithromycin solution at $298 \mathrm{~K}$ with $3-80 \mathrm{mg} / \mathrm{LHA}$. The suspensions were shaken on an orbit shaker at $180 \mathrm{r} / \mathrm{min}$ for $4 \mathrm{~h}$ at $298 \mathrm{~K}$ and filtered through $0.45 \mu \mathrm{m}$ membrane. The filtrate was measured with HPLC and $\mathrm{pH}$ and HAe ffect on roxithromycin adsorbed by MWCNT were analysed. 


\section{Results and Discussion}

\section{Adsorption kinetics}

The adsorption kinetics describe the rate of roxithromycin uptake on the MWCNT, which controls the equilibrium time. The kinetics parameters are helpful for the prediction of adsorption rate, which gives important information for designing and modeling the processes. The kinetics of the adsorption data were analyzed using different kinetics models: pseudo-first-order equation, and pseudo-second-order equation .

Pseudo-first-order equation is the most popular kinetics equation. The form is:

$$
\log \left(q_{\mathrm{t}}-q_{\mathrm{e}}\right)=\log q_{\mathrm{e}}-k_{1} \cdot t / 2.303
$$

pseudo-second-order equation:

$$
t / q_{\mathrm{t}}=1 / v_{0}+t / q_{\mathrm{e}} ; \quad v_{0}=k_{2} \cdot q_{\mathrm{e}}^{2}
$$

where $q_{\mathrm{t}}(\mathrm{mg} / \mathrm{g})$ is the mass of metal adsorbed at time $t(\mathrm{~min})$ and $q_{\mathrm{e}}(\mathrm{mg} / \mathrm{g})$ is the mass of metal adsorbed at equilibrium; $k_{1}(/ \mathrm{min}), k_{2}(\mathrm{~g} /(\mathrm{mg} \cdot \mathrm{min})), k_{3}(\mathrm{mg} /(\mathrm{g} \cdot \mathrm{min}))$ are the rate constants of the equation.

The kinetic curve of roxithromycin alone (Fig 1) showed that the adsorption rate was faster in $100 \mathrm{~min}$, then with the increase of adsorption capacity, the adsorption balance reached at $120 \mathrm{~min}$.

At the start of the adsorption, roxithromycin firstly adsorbed to the external cavity surface of the carbon nanotubes, adsorption capacity gradually rise, after the outside surface adsorption was saturate, and pass into the inner surface of the carbon nanotube until adsorption saturation. The experimental data were fitted with the model of the quasi-first and second-order dynamics model, and the results were shown in table 1 :

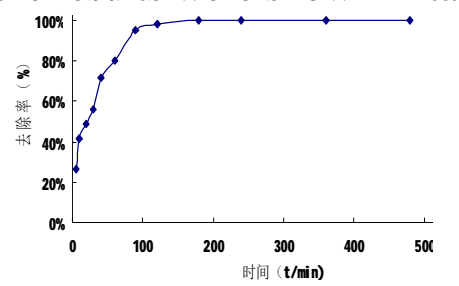

Fig.1 Effect of time on roxithromycin

Table1 The kinetic model fitting equations and parameters

\begin{tabular}{cccc}
\hline $\begin{array}{c}\text { kinetic } \\
\text { model }\end{array}$ & fitting equation & $\begin{array}{c}\mathrm{k} \\
\left(\mathrm{g} \cdot \mathrm{mg}^{-1} \cdot \mathrm{h}^{-1}\right)\end{array}$ & $\mathrm{R}^{2}$ \\
\hline $\begin{array}{c}\text { pseudo-first } \\
\text { order rate }\end{array}$ & $\ln (\mathrm{qe}-\mathrm{qt})=-0.0316 \mathrm{t}+3.649$ & 1.8932 & 0.9835 \\
$\begin{array}{c}\text { pseudo-seco } \\
\text { nd order rate }\end{array}$ & $\mathrm{t} / \mathrm{q}_{\mathrm{t}}=0.0239 \mathrm{t}+0.0064$ & 0.0893 & 0.9984 \\
\hline
\end{tabular}

According to Tab.1, the linear correlation coefficient of roxithromycin was greater than 0.98 , and the whole adsorption process of carbon nanotube with roxithromycin was better described by the quasi-second-level dynamic model. Fig.2 is the adsorption kinetics curve of erythromycin and roxithromycin in water. It can be seen that erythromycin had a faster adsorption rate than roxithromycin and can reach the adsorption equilibrium earlier. roxithromycin adsorption rate made slower when erythromycin coexisted in comparison with roxithromycin alone adsorbed by carbon nanotubes, It due to that erythromycin firstly occupied adsorption site on the surface of the carbon nanotubes and easier to enter the carbon nanotube cavity, so the rapid adsorption equilibrium reached. 


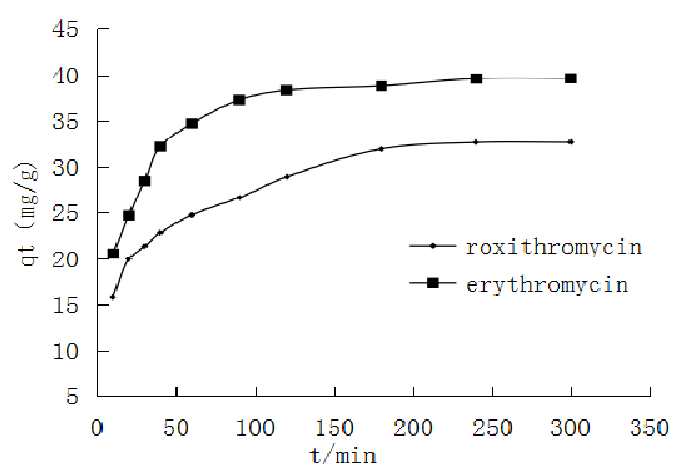

Table 2 The quasi-second kinetic model fitting equations and parameters

\begin{tabular}{cclc}
\hline antibiotic & \multicolumn{1}{c}{ Fitting equation } & $\mathrm{K}\left(\mathrm{g} \cdot \mathrm{mg}^{-1} \cdot \mathrm{h}^{-1}\right)$ & \multicolumn{1}{c}{$\mathrm{R}^{2}$} \\
\hline roxithromycin & $\mathrm{t} / \mathrm{qt}=0.0251 \mathrm{t}+0.8105$ & 0.0474 & 0.9791 \\
erythromycin & $\mathrm{t} / \mathrm{qt}=0.0251 \mathrm{t}+0.0526$ & 0.7216 & 0.9999 \\
\hline
\end{tabular}

Fig.2 Effect of time on roxithromycin and erythromycin

From Tab.2, the linear correlation coefficient of two kinds of antibiotics were greater than 0.95, using the quasi-second kinetic model can well describe the adsorption process of roxithromycin and erythromycin on carbon nanotubes, Tab. 3 showed that the adsorption rate constant of roxithromycin was lower when erythromycin coexisted than that of the roxithromycin exist alone.

\section{Adsorption isotherm}

Here the adsorption of roxithromycin on the surface of MWCNT was investigated. In this study, Langmuir and Freundlich adsorption isotherm were applied to fit the equilibrium data of adsorption of roxithromycin on the MWCNT. The linearized form of Langmuir equation is defined as the equation (3). The Freundlich model is formulated as the equation (4).

$$
\begin{aligned}
& 1 / Q_{\mathrm{e}}=1 /\left(b Q_{0} C_{\mathrm{e}}\right)+1 / Q_{0} \\
& \log Q_{\mathrm{e}}=\log k+1 / n \cdot \log C_{\mathrm{e}}
\end{aligned}
$$

Where $Q_{e}$ is the amount of solute roxithromycin adsorption on the adsorbent surface $\left(\mathrm{mg} \cdot \mathrm{g}^{-1}\right), C_{e}$ is the equilibrium concentration of roxithromycin in the solution $\left(\mathrm{mg} \cdot \mathrm{L}^{-1}\right), Q_{0}$ is the maximum surface density at monolayer coverage and $b$ is the Langmuir adsorption constant $\left(\mathrm{L} \cdot \mathrm{mg}^{-1}\right) . k$ is Freundlich constant $\left(\mathrm{mg} \cdot \mathrm{g}^{-1}\right)$ and $n$ is the hetergenity factor .

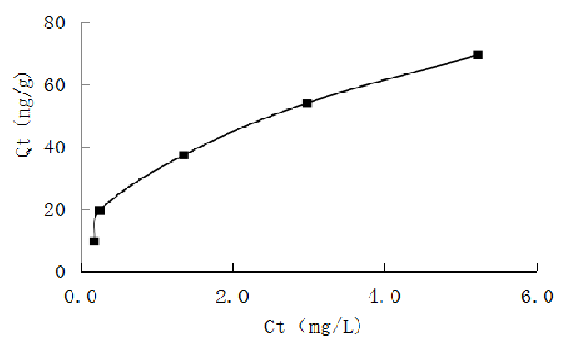

Table3 The parameters of Freundlich and Langmuir equation

\begin{tabular}{|c|c|c|c|c|c|c|}
\hline \multirow{2}{*}{$\mathrm{T}$} & \multicolumn{3}{|c|}{ Freundlich } & \multicolumn{3}{|c|}{ Langmuir } \\
\hline & $\mathrm{n}$ & $\mathrm{K}_{\mathrm{F}}$ & $\mathrm{R}^{2}$ & $\mathrm{Xm}$ & $a_{1}$ & $\mathrm{R}^{2}$ \\
\hline \multirow{2}{*}{298} & \multirow{2}{*}{1.9069} & \multirow{2}{*}{30.2883} & 0.954 & \multirow{2}{*}{84.0336} & \multirow{2}{*}{0.8264} & 0.951 \\
\hline & & & 2 & & & 5 \\
\hline
\end{tabular}
based on static adsorption data

Fig.3 Adsorption isotherms of roxithromycin

Fig.3 illustrated the adsorption isotherm of roxithromycin on MWCNT. All the correlation coefficient, $R^{2}$ values and the constants obtained from the two isotherm models applied for adsorption of roxithromycin on the MWCNT were summarized in Tab.3 .The Freundlich model fitted the experimental data as well as the Langmuir model, both were 0.95. This suggested that some heterogeneity on the surfaces or pores of the MWCNT played the role in roxithromycin adsorption. Tab. 3 also listed the maximum monolayer adsorption capacity $84 \mathrm{mg} / \mathrm{g}$ of roxithromycin on MWCNT. 


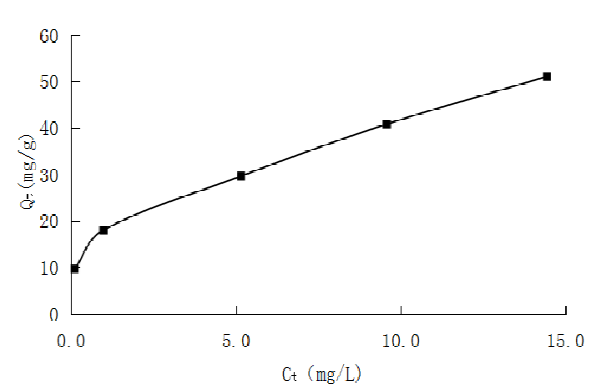

Fig. 4 Adsorption isotherms of roxithromycin

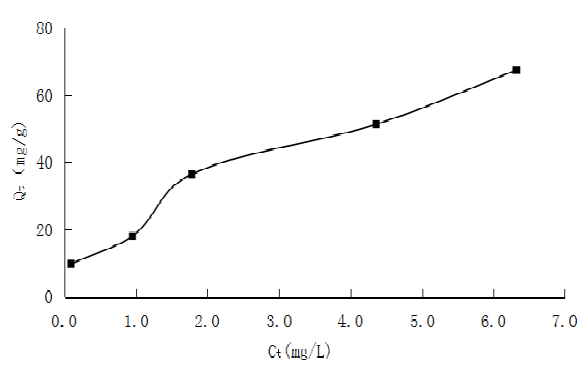

Fig.5 Adsorption isotherms of erythromycin

Table 4 The Freundlich equation and parameters of erythromycin and roxithromycin

\begin{tabular}{ccccc}
\hline antibiotic & Fitting equation & $\mathrm{n}$ & $\mathrm{K}_{\mathrm{F}}$ & $\mathrm{r}$ \\
\hline erythromycin & $\mathrm{LnQe}=0.2686 \operatorname{lnCe}+2.9606$ & 3.7194 & 18.9276 & 0.9702 \\
roxithromycin & $\mathrm{LnQe}=0.4641 \operatorname{lnCe}+3.5503$ & 2.1547 & 33.9994 & 0.9010 \\
\hline
\end{tabular}

Fig.4 and Fig.5 illustrated respectively the adsorption isotherm of roxithromycin and erythromycin on MWCNT. Results showed that the adsorption capacity of roxithromycin on MWCNT obviously decreased when roxithromycin and erythromycin coexisted in the solution. The Freundlich model fitted the experimental data of roxithromycin and erythromycin, both were over 0.9. This suggested that Freundlich model could fitted well the adsorption process. $\mathrm{K}_{\mathrm{F}}$ of roxithromycin was lower than $\mathrm{K}_{\mathrm{F}}$ of erythromycin which indicated that adsorption strength on roxithromycin was less than on erythromycin. While the $\mathrm{n}$ was more than 1 , the adsorption process was favorable adsorption.

\section{Effect of pH}

The chemical form of adsorbent and adsorbate would change with $\mathrm{pH}$ variation which influenced the adsorption performance. Fig 8 . indicated that adsorption capacity decreased when $\mathrm{pH}<4$, While adsorption capacity increased when $\mathrm{pH}>4$, the adsorption capacity of $34.88 \mathrm{mg} / \mathrm{g}$ was maximum when $\mathrm{pH}=11$. Roxithromycin was alkalescence chemical which was unsteady and apt to hydrolysied in acid condition.

At $\mathrm{pH}<7$, the species of roxithromycin predominantly existed in ions. With the increase of $\mathrm{pH}$ value, the ions and molecule coexisted in water. At $\mathrm{pH}>9$, the species of roxithromycin predominantly existed in free molecule.The carboxyl group of carbon nanotubes was easy to generate hydrogen bonds under low $\mathrm{pH}$ value, and reduced the formation of hydrogen bonds under high $\mathrm{pH}$ value because of ionization. Adsorption performance of roxithromycin on carbon nanotubes enhanced because of hydrogen bonding production. Carbon nanotubes were positively charged in $\mathrm{pH}=1$, which can produce electrostatic attraction with negatively charged roxithromycin, further increased the adsorption capacity. With the increase of $\mathrm{pH}$ value, the role of the hydrogen bonds weakened gradually. The carbon nanotube surface was negatively charged, and repulsion effect happened with roxithromycin , which was not conducive to the adsorption and adsorption capacity therefore continue to decrease. When the $\mathrm{pH}>7$, because the roxithromycin free molecules increased, the mass transfer driving force increased, the absorption rate accelerated, thus improved the adsorption quantity.

\section{Effect of HA}

Fig 8.showed that roxithromycin adsorption on multi-walled carbon nanotube is slowly promoted by humic acid when humic acid concentration was lower than $25 \mathrm{mg} / \mathrm{L}$, inhibition of multi-walled carbon nanotubes was found on roxithromycin adsorption when humic acid concentration was greater than $25 \mathrm{mg} / \mathrm{L}$, roxithromycin adsorption capacity gradually reduce to the lowest level of $24.3 \mathrm{mg} / \mathrm{g}$. 
One of the reasons was that low concentration humic acid plays a role in the adsorption bridge, which increased the dispersion of nanometer materials in water, thus enhancing the adsorption effect. On the other hand, roxithromycin have very strong hydrophobicity, and the structure of the humic acid was favour to adsorption of hydrophobic material. The lower oxygen content of humic acid, the less adsorption on hydrophobic new material ${ }^{[18]}$.

Therefore, the adsorption of roxithromycin was promoted when the humic acid concentration was less than $25 \mathrm{mg} / \mathrm{L}$. With the increase of humic acid concentration, humic acid and roerythromycin can produce competitive adsorption and compete with each other on the surface of multi-walled carbon nanotubes. Although humic acid has some adsorption capacity for roxithromycin, the surface area of humic acid is much smaller than the surface area of carbon nanotube, resulting in the decrease of roxithromycin adsorption.

Moreover, the adsorption capacity of roxithromycin was further reduced when the size of the humic acid molecule was larger and the larger surface area of the carbon nanotube was taken up . Humic acid containing negative charge, and the multi-walled carbon nanotube adsorbs humic acid, which increases the negative charge on the surface of the carbon nanotubes. There was negative charge on roxithromycin, so the electrostatic attraction between the carbon nanotubes and roerythromycin would be weaken ${ }^{[18]}$.

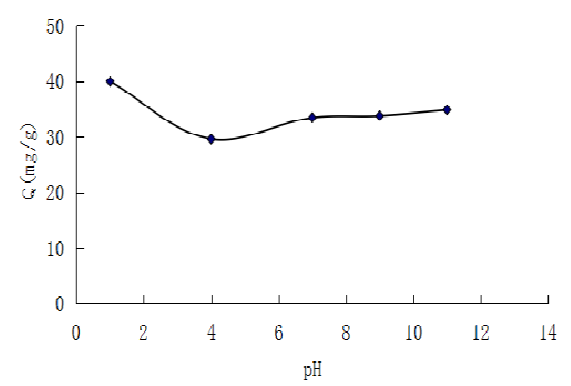

Fig.6 Effect of $\mathrm{pH}$ value on roxithromycin

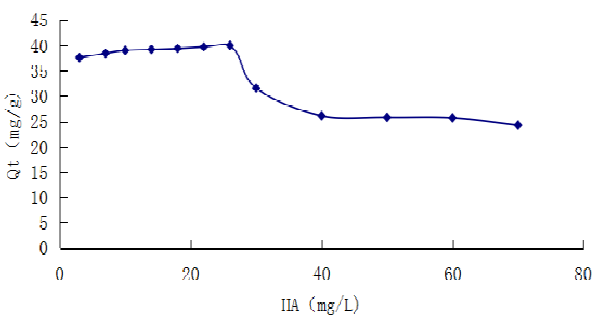

Fig.7Effect of HA on roxithromycin

\section{Conclusions}

Multi-walled carbon nanotubes has good adsorption ability to the roxithromycin, the process can be well fit by the Freundlich isothermal adsorption equation. The kinetics of the adsorption process was found to follow the pseudo-second-order kinetic model with high correlation. When erythromycin was coexist in the solution, the adsorption quantity and adsorption rate of roxithromycin were significantly reduced. The adsorption of roxithromycin in the multiwalled carbon nanotube was affected by $\mathrm{pH}$ value, and the adsorption of roerythromycin decreased gradually at $\mathrm{pH}<4$. The adsorption qu antity of roerythromycin increased at $\mathrm{pH}>4$, when $\mathrm{pH}=11$, reached at a maximum. The adsorption of roxithromycinon on the multiwalled carbon nanotubes was affected by the presence of humic acid, when the concentration of humic acid was less than $25 \mathrm{mg} / \mathrm{L}$, the adsorption of roxith romycin on multi-walled carbon nanotubes was slow incentive, when humic acid concentration was greater than $25 \mathrm{mg} / \mathrm{L}$, the adsorption process was inhibited, adsorption capacity of roxithromycin on multiwalled carbon nanotubes gradually reduced.

\section{References:}

[1] Fu H, Li XB, Wang J, et al.,Activated carbon adsorption of quinolone antibiotics in water: Performance, mechanism, and modeling, Journal of environmental sciences,2017,(56):145-152

[2]Wu JR, Zhao HY, Chen R.Adsorptive removal of trace sulfonamide antibiotics bywater-dispersible magnetic reduced graphene oxide-ferrite hybridsfrom wastewater. Journal of Chromatagraphy B,2016,1029-1030:106-112.

[3] Carvalho, I.T., Santos, L.. Antibiotics in the aquatic environments: a review of the European 
scenario. Environ. Int., 2016(94), 736-757.

[4] Ahmed M.B , Zhou J. L. , Ngo H.H et al.,Competitive sorption affinity of sulfonamides and chloramphenicol antibiotics toward functionalized biochar for water and wastewater treatment Bioresource Technology. 2017 (238) 306-312.

[5] $\mathrm{Fu} \mathrm{H}, \mathrm{Li} \mathrm{B}$, Wang J, et al.,Activated carbon adsorption of quinolone antibiotics in water: Performance, mechanism, and modeling. Journal of environment science,2017(56):145-152.

[6] Osinska, A., Harnisz, M., Korzeniewska, E.,. Prevalence of plasmid-mediated multidrug resistance determinants in fluoroquinolone-resistant bacteria isolated from sewage and surface water. Environ. Sci. Pollut. Res. 2016(23), 10818-10831.

[7] Wu J R, Zhao H Y, Chen R et al.. Adsorptive removal of trace sulfonamide antibiotics bywater-dispersible magnetic reduced graphene oxide-ferrite hybridsfrom wastewater. Journal of Chromatography B, 2016 (1029-1030) 106-112.

[8] Harnisz, M., Korzeniewska, E., Golas, I.. The impact of a freshwater fish farm on the community of tetracycline-resistant bacteria and the structure of tetracycline resistance genes in river water. Chemosphere 2015(128), 134-141.

[9] Wang, B., Jiang, Y.S., Li, F.Y., Yang, D.Y.. Preparation of biochar by simultaneous carbonization, magnetization and activation for norfloxacin removal in water. Bioresour. Technol. , 2017(233), 159-165.

[10] Zhao, H., Liu, X., Cao, Z.,et al., Adsorption behavior and mechanism of chloramphenicols, sulfonamides, and nonantibiotic pharmaceuticals on multi-walled carbon nanotubes. J. Hazard. Mater. 2016.(310), 235-245.

[11]Watkinson A J, Murby E J, Kolpin D W, et al. The occurrence of antibiotics in an urban watershed: From wastewater to drinking water [J]. The Science of the Total Environment, 2009, 407(8):2711 $\sim 2723$.

[12] Yang S, Carlson K H. Solid-phase extraction-high-performance liquid chromatography-ion trap mass spectrometry for analysis of trace concentrations of macrolide antibiotics in natural and wastewater matrices[J].Journal of Chromatograph1y A, $2004,1038: 141 \sim 155$.

[13] Xu W H, Zhang Q, Chun Z,et al. Antibiotic content and seasonal variation in water of Hong Kong's Victoria Harbour and the Pearl River in Guangzhou [J]. Environmental Science .2006, 27 (12): $2458 \sim 2462$.

[14] Kim H J, Kim D E. MD simulation of the frictional behavior of CNTs with respect to orientation[J]. Tribology International, 2012, 50(3): 51-56.

[15] Li YH, Wang SG, Wei JQ,et al.. Lead adsorption on carbon nanotubes. Chemical physics Letters 2002,357,(3-4),263 266 .

[16]Wang H J, Zhou A L, Peng F, et al.. Adsorption characteristic of acidified carbon nanotubes for heavy metal $\mathrm{Pb}$ (II) in aqueous solution. Materials Seience and Engineering: A 2007,466,(1-2),201 206.

[17] Shen X E. The adsorption properties research of nitro compounds and antibiotics on MWCNTs [D]. Shandong: Jilin University, 2009.

[18]Yu F, Li Y, Han S, et al..Adsorption removal of antibiotics from aqueous solution using carbon materials. Chemosphere 2016(153):365-385. 